\title{
NUEVAS NOTICIAS SOBRE JULIO SORMANO
}

\author{
POR \\ MARÍA JOSÉ REDONDO CANTERA \\ Universidad de Valladolid
}

The work and the artistic personality of Julio Sormano, who worked under the leadership of Pompeo Leoni in Spain, remains scarcely known. In this article the possible family relations with Giovanni Antonio Sormano are considered, as well as the date and the way of his arrival in Spain, and his collaboration in the Valdes' tombs. In 1584 he made the bronze slab of don Bernabé, bishop of El Burgo de Osma (Soria), formerly commissioned to grille-masters Rodríguez and Plaza.

\section{Julio Sormano, colaborador de Pompeyo Leoni}

Durante más de un siglo lo único conocido de Julio Sormano fueron los datos publicados por Plon en su estudio sobre los Leoni, es decir, su procedencia romana y su intervención en 1582 en el transporte de las piezas de los sepulcros de don Fernando Valdés, arzobispo de Sevilla e Inquisidor general, y de sus padres ${ }^{1}$, que habían sido contratados por Pompeyo en $1576^{2}$.

Por el momento no tenemos datos que nos permitan fijar con exactitud la filiación de Julio Sormano. Varios artistas, sobre todo escultores, portadores de este apellido estuvieron activos durante los siglos XVI y XVII en Italia y en España ${ }^{3}$. Babelon pensó que Julio había sido herma-

\footnotetext{
${ }^{1}$ Plon, Eugène, Leon Leoni sculpteur de Charles Quint et Pompeo Leoni sculpteur de Philippe II, París, 1887, pp. 407409 y 413 . La mayor parte de la bibliografía sobre estos sepulcros se puede encontrar en NEUMANN, Mechtild, Pompeo Leoni-Um 1530-1608. Ein italienischer bildhauer am hofe Philipps II von Spanien, Bonn, 1997, p. 299.

${ }^{2}$ García Chico, Esteban, «Nuevos documentos para el estudio del arte en Castilla. Escultores. siglo XVI», B.S.A.A., t. XXIV, 1958, pp. 168-170.

${ }^{3}$ Sobre el más destacado de todos ellos, Leonardo Sormanni da Sarzano († 1589), vid. Venturi, A., Storia dell' Arte italiano, t. X, III, Milán, 1937, pp. 586-591. Acerca de artistas con el apellido Sormano, vid. Thieme, Ulrich y Becker, Felix, Allgemeines Lexikon der Bildenden Künstler, t. XXXI, Leipzig, pp. 296-298. Sobre Juan Antonio, escultor especializado en la labra del mármol, que trabajó al servicio de Felipe II realizando varios trabajos decorativos y fuentes en palacios y jardines reales, vid. infra. Entre 1637 y 1654 está atestiguada la presencia en nuestro país de otro marmolista portador de este apellido, de nombre Juan Francisco, vid. Martín Ortega, Alejandro, «Notas tomadas de escrituras del Archivo Histórico de Protocolos de Madrid», t. I, pp. 221 y 221 vº y Agulló y Cobo, Mercedes, Documentos sobre escultores, entalladores y ensambladores de los siglos XVI al XVIII, Valladolid, 1978, p. 152.
} 
no de Juan Antonio Sormano ${ }^{4}$. Este escultor, al que a su vez se cree hermano de Leonardo Sormano, llegó a España en 1562 y pronto alcanzó el título de escultor del rey ${ }^{5}$. Casó en primeras nupcias con Constanza de Godoy, de la que tuvo un hijo llamado Luis ${ }^{6}$. Tras enviudar, contrajo nuevo matrimonio con Juana de Figueroa en $1574^{7}$, de cuya unión nació por esos años Lucrecia Antonia de Figueroa ${ }^{8}$. Sobrino suyo fue Bautista Berberi ${ }^{9}$. Tuvo su casa y su taller en la madrileña carrera de San Francisco ${ }^{10}$, calle donde también vivió Pompeyo Leoni ${ }^{11}$. Al final de su vida también trabajó como ingeniero hidráulico en el Puente de Segovia ${ }^{12}$. En ninguno de los documentos que proporcionan estos datos, ni siquiera en los relativos a su familia ni en su testamento ${ }^{13}$, redactado poco antes de su muerte en 1575 , aparece mencionado Julio $^{14}$.

Julio Sormano pudo llegar a España a finales de la década de 1570 formando parte de esa treintena de «oficiales italianos» que trabajó en El Escorial y de la que sólo quedaba menos de la mitad en 1583, por haber muerto el resto en ese corto intermedio ${ }^{15}$. Sormano no aparece entre los supervivientes de ese grupo, aunque faltan algunos nombres por mencionar en el documento que da noticia de ello. Otra posibilidad es que viniera al amparo de Juan Antonio, habida cuenta de su apellido ${ }^{16}$-lo que tendría que haber sucedido con anterioridad a 1575 -, o de los Leoni —en torno a 1580 - ya que trabajó a las órdenes de Pompeyo. En cualquier caso, a la luz

${ }^{4}$ Babelon, Jean, Jacopo da Trezzo et la construction de L' Escurial. Essai sur les arts à la cour de Philippe II. 15181589, Burdeos-París, 1922, p. 101. Noticias relativas a Juan Antonio Sormano ya fueron publicadas por Ceán Bermúdez, Juan Agustín, Diccionario histórico de los más ilustres profesores de las Bellas Artes en España, t. IV, Madrid, 1800, pp. 388-389; más recientemente han tratado sobre él Rivera Blanco, Javier, Juan Bautista de Toledo y Felipe II. La implantación del clasicismo en España, Valladolid, 1984, passim; Deswarte-Rosa, Sylvie, «Le cardinal Ricci et Philippe II: cadeaux d' oeuvres d' art et envoi d' artistes», Revue de l' Art, n. ${ }^{\circ} 88,1990$, p. 54; Estella, Margarita «Sobre las esculturas del jardín de la Isla en Aranjuez», en Velázquez y el arte de su tiempo, Madrid, 1991, p. 338; Martín González, Juan José, El escultor en palacio (Viaje a través de la escultura de los Austrias), Madrid, 1991, p. 85; Checa, Fernando, Felipe II mecenas de las artes, Madrid, 1992, passim y Estella, Margarita, «Algo más sobre Pompeyo Leoni», A.E.E., t. LXVI, n..$^{\circ} 262$, 1992, p. 140.

5 Martín González, Juan José, op. cit., p. 85.

${ }^{6}$ A. H. de P. de Madrid, leg. 985 , fols. 340 y ss.

${ }^{7}$ Carta de dote entre Juan Antonio Sormano y Juana de Figueroa, A. H. de P. de Madrid, leg. 787, fols. 205 y ss.

${ }^{8}$ En 1589, cuando contaba unos dieciséis años, se encontraba en Roa, al servicio de la Condesa de Siruela. Por entonces madre e hija mantuvieron un pleito entre sí por ciertas diferencias económicas, por lo que Juana de Figueroa renunció a la custodia de la menor, A. H. de P. de Madrid, leg. 1467, 4, fols. 1269 y 1275. En 1598 Lucrecia había ingresado en el convento de la Concepción de Valladolid, A. H. de P. de Madrid, leg. 815, fol. 953-957.

9 A. H. de P. de Madrid, leg. 1185, pleito sobre la partición de bienes tras la muerte de Juan Antonio Sormano. La referencia fue dada por Pérez Pastor, Cristóbal, «Colección de documentos inéditos para la historia de las Bellas Artes en España», Memorias de la Real Academia Española, t. XI, Madrid, 1914, p. 34.

${ }^{10}$ A su muerte heredó estas casas principales su hijo Luis, A. H. de P. de Madrid, leg. 832, fols. 258-281 y leg. 985 , fols. 340 y ss.

11 Plon, Eugène, op. cit., p. 405 y Estella, Margarita, «Algo más...», pp. 138-139.

12 En 1574 contrataba la construcción de ocho cepas para el Puente de Segovia en Madrid, de las que no pudo hacer más que tres antes de morir, al año siguiente, vid. Bustamante García, Agustín, «En torno a Juan de Herrera y la Arquitectura», B.S.A.A., t. XLII, 1976, pp. 235-236 y Estella , Margarita, «Algo más...», p. 140. Como testimonio de esta actividad, al contraer su segundo matrimonio, en 1574, se tituló «ingeniero de Su Majestad», vid. nota 7.

${ }^{13}$ Pérez Pastor, Cristóbal, op. cit., p. 22. Debió de fallecer a finales de octubre o principios de noviembre de 1575, vid. nota 12

${ }^{14}$ Proske, Beatrice Gilman, Pompeo Leoni. Work in marble and alabaster in relation to Spanish sculpture, Nueva York, 1956, p. 29, señaló la ausencia de mención de Julio en el testamento de Juan Antonio.

${ }^{15}$ Petición de ayuda económica a Felipe II por parte de varios marmolistas italianos, fechada el 19 de marzo de 1583, publicada por Portabales Pichel, Amancio, Maestros mayores, arquitectos y aparejadores de El Escorial, Madrid, 1952, pp. 304-305. La elevada mortalidad de los canteros hizo aún más necesario el reclutamiento de maestros, como se expone en el «Memorial de Jacome de Trezzo, Pompeo Leoni y Bautista Comane al Rey...», R.A.B.M., t. V, 1875, p. 67.

${ }^{16}$ Deswarte-Rosa, Sylvie, op. cit., p. 54, da por supuesto que Julio fuera hermano de Juan Antonio y que fuera llamado por éste para trabajar en la corte de Felipe II. 
de los datos aportados por Estella, su llegada sería anterior a la del grupo de marmolistas que, procedentes de Génova, empezaron a laborar en El Escorial a principios de 1582, entre los que tampoco figura su nombre, como tampoco entre los que se añadieron en $1583^{17}$.

Dada la importancia de la tarea que Pompeyo Leoni asignó a Julio Sormano en su ausencia, Plon consideró que éste fue uno de sus colaboradores ${ }^{18}$. Habría sido lógico, pues, que su nombre apareciera entre los artistas que participaron de modo significativo en la obra del milanés para El Escorial. Pero ni la exhaustiva recopilación documental de Andrés ${ }^{19}$, ni las amplias investigaciones que se han realizado en los últimos años en torno a los Leoni, El Escorial y Felipe II, y que han dado a conocer múltiples datos sobre los numerosos escultores que trabajaron en las obras reales en colaboración o bajo las órdenes de Pompeyo, o de Jacome da Trezzo ${ }^{20}$, recogen su nombre, ni en los fondos archivísticos del monasterio ni en los de la Casa Real, incluidos los relativos al taller de los Leoni en Milán ${ }^{21}$. Bien es cierto que aunque en la documentación relativa a El Escorial aparezcan datos de artistas que intervinieron en su decoración, muchos de estos oficiales y marmolistas habían sido contratados particularmente por Leoni, Comane y Trezzo, y carecían de relación laboral o económica directa con la Administración Real o la Congregación del Monasterio ${ }^{22}$. En esta situación pudo encontrarse Julio Sormano, aunque la mayor parte de las pocas noticias que tenemos de él indican que su actividad se orientó más bien a cumplir con encargos procedentes de una clientela privada, contratados por Pompeyo o por él mismo.

El primero de los datos, desde el punto de vista cronológico, que poseemos de Sormano, ha sido proporcionado recientemente por Estella, quien, a propósito de sus estudios sobre los Leoni, ha dado a conocer el contenido de un importante documento para el establecimiento de la formación y de la actividad artística de este escultor en España. Un poder otorgado por Pompeyo, antes de salir de Madrid con destino a Italia, testimonia que en el mes de marzo de 1582 Julio Sormano formaba parte del taller de Pompeyo, al igual que Juan Ruiz Francés, Francisco del Gasto y Domingo Martín, entre otros ${ }^{23}$. Para entonces Leoni, que se disponía a

17 Bustamante García, Agustín, «Las estatuas de bronce del Escorial. Datos para su historia», Anuario del Departamento de Historia y Teoría del Arte, vol. VI, 1994, pp. 166-169 y 171-173 y García, Eloísa, «La obra en bronce hecha en Italia para el retablo y tabernáculo de San Lorenzo el Real del Escorial», B.S.A.A., t. XII, 1945-1946, pp. 136-139.

18 Plon, Eugène, op. cit., p. 208.

19 Andrés Martínez, Gregorio de, Inventario de documentos sobre la construcción y ornato del Monasterio de El Escorial existentes en el Archivo de su Real Biblioteca, Anejo de A.E.A., Madrid, 1972.

${ }^{20}$ Citaremos, por orden cronológico de publicación, solamente las más destacadas: Martín González, Juan José, op. cit.; Checa, Fernando, op. cit.; Bustamante García, Agustín, «Las estatuas...», Anuario..., vols. V, VI y VII-VIII, 1993 a 1996, pp. 41-57, 159-177 y 69-86, respectivamente, y La octava maravilla del mundo (Estudio histórico sobre El Escorial de Felipe II), Madrid, 1994; Cano de Gardoqui y García, José Luis, La construcción del monasterio de El Escorial. Historia de una empresa arquitectónica, Valladolid, 1994; y CONTI, Barbara Paola, «Madrid-Milano. Scapellini e scultori per il «Retablo mayor». Prime annotazioni», Actas del Simposium «La escultura en el monasterio del Escorial», San Lorenzo del Escorial, 1994, pp. 329-342.

${ }^{21}$ Quiero dejar constancia de mi agradecimiento a mi buen amigo y compañero, el Dr. Cano de Gardoqui, con quien he hablado y consultado largamente sobre este tema, dado su conocimiento de los fondos documentales relativos a El Escorial que se custodian en el Archivo General de Simancas.

${ }_{22}$ En la respuesta al primer documento citado en la nota 15 se afirmaba que estos oficiales «andan por su cuenta» y que eran pagados por los maestros que habían contratado la obra. Este sistema organizativo del trabajo ha sido estudiado por Cano de Gardoqui y García, José Luis, «Datos para la escultura cortesana del último tercio del siglo XVI. Aspectos socioeconómicos», B.S.A.A., t. LVI, 1990, p. 474 y La construcción del monasterio..., p. 356. A este respecto, vid. también el documento publicado por Portabales Pichel, Amancio, Los verdaderos artífices de El Escorial y el estilo indebidamente llamado Herreriano, Madrid, 1945, pp. CXXXVIII-CXXXIX.

${ }^{23}$ Estella, Margarita, «Los Leoni, escultores entre Italia y España», Catálogo de la exposición «Los Leoni (1509-1608). Escultores del Renacimiento italiano al servicio de la corte de España», Madrid, 1994, pp. 55-56 y «El retablo mayor de la basílica», Actas del Simposium..., p. 114. Una sumaria referencia al documento se encontraba en Pérez Pastor, Cristóbal, op. cit., p. 39. 
partir hacia Milán para fundir las estatuas con destino al retablo de El Escorial, afirmaba que ya tenía hecha la mayor parte de las piezas de bronce de la custodia ${ }^{24}$, aunque sin duda se refería sobre todo a los elementos arquitectónicos ${ }^{25}$. En dicha operación le habían ayudado los oficiales mencionados, los cuales, en palabras de Leoni, sabían «deste ministerio lo neçesario para proseguir la dicha obra porque an estado conmigo y aprendido en mi casa mas de tres años». Otro documento redactado por esas fechas confirma que Julio Sormano vivía en casa de Pompeyo ${ }^{26}$.

A juzgar por este dato, en 1582 Julio Sormano tenía ya una sólida formación como escultor de bronce. Por otra parte, señala el año de 1579, a lo más tardar, como el del comienzo del trabajo de Julio Sormano junto a Pompeyo Leoni y quizá también, el de su llegada a España. Significativamente, la fecha coincide con el contrato de la custodia, el retablo y los sepulcros de El Escorial por Jacome da Trezzo, Juan Bautista Comane y Pompeyo Leoni. Como se ha dicho más arriba, llamados por éstos o atraídos por la demanda de marmolistas y de broncistas para llevar a cabo esos trabajos y otros para el monasterio filipino, se desplazaron a la Corte española artífices italianos cualificados en esas actividades, entre los que pudo encontrarse Julio Sormano. Consta que en 1582 éste tuvo amistad o tratos económicos con el cantero milanés Cristóbal Carlón, o Carlone ${ }^{27}$, padre del también maestro de cantería Bartolomé Carlón, que había fallecido dos años antes, tras haber trabajado en el puente de Segovia, respaldado por la fianza de Pompeyo Leoni ${ }^{28}$, y en El Escorial ${ }^{29}$.

A partir de la presencia de Julio Sormano como testigo en los diversos documentos que otorgó Pompeyo en sus últimos días de estancia en nuestro país en $1582^{30}$, Babelon dedujo que Sormano era hombre de confianza de Leoni ${ }^{31}$. Tal extremo queda confirmado por quedarse encargado, tras la marcha del milanés, de la obra más importante que tenía Pompeyo entre manos, con excepción de sus trabajos para el rey, los sepulcros de la familia Valdés.

Aunque lo previsto era que, partido el maestro a Milán, sus oficiales pasaran a trabajar al taller de Jacome da Trezzo, bajo la supervisión de Juan de Valencia, Sormano pasó a ocuparse de los sepulcros de los Valdés. La mayor parte de los elementos de éstos habían sido esculpidos junto a las canteras de alabastro de Aleas (Guadalajara) ${ }^{32}$ y allí aguardaban su traslado hasta su lugar de destino, en Salas (Asturias). En 1582, poco antes de su partida, Leoni había contratado ciertas mejoras en el sepulcro con los testamentarios del Inquisidor, consistentes en la utilización de alabastro para la caja de los nichos ${ }^{33}$. Es aquí donde puede asegurarse la intervención de Julio Sormano, pues con anterioridad resulta problemático admitirla. Proske observó la menor ca-

\footnotetext{
24 Estella Marcos, Margarita, «El retablo mayor...», p. 117.

25 A principios de 1582 Leoni se ocupaba del dorado de las basas y los capiteles de las columnillas de la Custodia, en las que trabajaba desde 1580 , así como de la fundición de otras piezas sin especificar, «Carta autógrafa de Jacome de Trezzo a Juan de Herrera...», R.A.B.M., t. V, 1875, p. 84 y Andrés, Gregorio de, «Inventario de documentos del siglo XVI sobre El Escorial que se conservan en el Archivo del Instituto "Valencia de Don Juan" (Madrid)», Ciudad de Dios, vol. CXCIV, 1981 , p. 568.

26 Vid., nota 11.

27 Ibídem.

28 En noviembre de 1575 Bartolomé Carlón, vecino por entonces de Almazán (Soria), se comprometió a hacer cinco cepas para el puente, lo que completaría las ocho que había contratado Juan Antonio Sormano. Pompeyo Leoni salió como su fiador, A. H. de P. de Madrid, leg. 741, fols. 855 y 862.

${ }^{29}$ Bustamante García, Agustín, La octava maravilla..., p. 330.

30 Con fechas de 3, 10 y 15 de marzo de 1582, Plon Eugène, op. cit., pp. 399, 408, 400 y 395-397, respectivamente.

31 Babelon, Jean, op. cit., p. 101.

32 Aunque en el contrato, firmado en diciembre de 1576, se había especificado que el sepulcro se esculpiría en Madrid, García Chico, Esteban, op. cit.

33 Pérez Pastor, Cristóbal, op. cit., p. 35 y Benito Ruano, Eloy, «El sepulcro del Arzobispo Valdés por Pompeyo Leoni en la colegiata de Salas (Asturias)», Simposium Valdés-Salas, Oviedo, 1968, p. 283-284.
} 
lidad de la escultura del Inquisidor con respecto a otras obras de Leoni de la misma época, por lo que pensó que gran parte del trabajo había corrido a cargo de los marmolistas que, siguiendo la traza y las directrices del maestro, habían esculpido las piezas al pie de la cantera ${ }^{34}$. Cabría suponer que Sormano figurara entre esos oficiales, pero hasta ahora sólo tenemos constancia de que el romano estuviera trabajando con Leoni desde 1579, mientras que al parecer el encargo de Salas estaba casi terminado en septiembre de $1578^{35}$. En 1582, tanto antes de su salida de Madrid como al poco tiempo de su llegada a Milán, Pompeyo otorgó sendos poderes a Cornelio Carnago, secretario de la Colecturía del Papa, para que se ocupara de los aspectos económicos que quedaban pendientes con respecto a los sepulcros de los Valdés. En mayo Sormano recibió un poder de Carnago para que pudiera formalizar compromisos relativos al transporte de las distintas piezas que componían los monumentos y contrató el acarreo desde Aleas a Salas ${ }^{36}$. Que había quedado encargado de la supervisión de la operación queda confirmado por las palabras del propio Leoni, pues todo debía efectuarse «conforme a la horden e ynstruicion que para ello tengo dada a Julio Sormano y a otros» ${ }^{37}$.

Sormano organizó el transporte por lo menos hasta León. Pero hubo un cambio en el itinerario previsto, o bien una adición de piezas. Según el concierto firmado entre Sormano y los carreteros, los alabastros de los sepulcros Valdés no podían modificarse en su embalaje ni descargarse de los carros hasta llegar a su destino. Consta, sin embargo, que en 1583 partieron de Valladolid, con dirección a León, quince carros con diversas piezas «para el tumulo e capilla que se haze en la villa de salas... del arcobispo don fernando de valdes». Entre ellas iban las esculturas de la Prudencia, la Fortaleza y otra figura sin identificar ${ }^{38}$. Esta última podría haber sido la Esperanza o la Caridad, pues era de mayor tamaño que las anteriores, ya que pesaba cuarenta y cuatro arrobas, frente a las treinta y tres y a las treinta y ocho arrobas de las otras. Si en el acuerdo establecido para este transporte se mencionaba la identidad de las representaciones, es lógico pensar en una manipulación de estas piezas en Valladolid, de alcance desconocido hasta ahora. Proske observó la semejanza existente en los plegados de los paños con los que se cubren la pareja de Virtudes situada a la derecha en el ático del arco sepulcral del Inquisidor y el estilo de Esteban Jordán ${ }^{39}$. Conocida ahora la etapa vallisoletana en el trayecto del sepulcro, cobra fuerza la hipótesis de la intervención parcial de un escultor activo en Valladolid o de una asimilación de formas vigentes en el foco artístico de la ciudad.

A partir de entonces Sormano dejó de estar vinculado a los sepulcros de Salas. A finales de 1583 había dejado sin pagar a los carreteros contratados en Valladolid y no se hallaba en Madrid. Quizá ya se encontraría en El Burgo de Osma. Doña Mariana de Sotomayor, que había quedado al cuidado de muchos de los asuntos económicos de Pompeyo en España ${ }^{40}$, se ocupó de saldar la mayor parte de la deuda con los carreteros, mientras que César Villa, el mejor entre los escultores que tenía Leoni a su servicio en Milán ${ }^{41}$, se encargó del asentamiento del sepulcro a partir del año siguiente. Trabajó en ello en 1584-1585 ${ }^{42}$. La diferencia de calidad entre la figu-

\footnotetext{
${ }^{34}$ Proske, Beatrice Gilman, op. cit., p. 21.

${ }_{35}$ Pérez Pastor, Cristóbal, op. cit., p. 27.

${ }^{36}$ Plon, Eugène, op. cit., p. 409.

${ }^{37}$ Plon, Eugène, op. cit., p. 413. Una corrección en la lectura del documento en Benito Ruano, Eloy, op. cit., p. 285.

38 A. H. de P. de M., leg. 956, fol. 427-428.

${ }^{39}$ Proske, Beatrice Gilman, op. cit., p. 19.

${ }^{40}$ Estella Marcos, Margarita, «La mujer y el arte en los documentos de los siglos XVI y XVII: Los miembros femeninos de la familia Leoni», VII Jornadas de Arte. La mujer en el arte español, Madrid, 1997, pp. 126-129.

${ }^{41}$ Babelon, Jean, op. cit., p. 155.

${ }^{42}$ Había sido contratado para ello por Leoni en junio de1583. Se ocupó en esta tarea al menos desde abril de 1584. En marzo de 1585 lo abandonó y fue demandado por Mariana de Sotomayor, Cf. Agulló y Cobo, Mercedes, op. cit., pp. 94-
} 95. 
ra orante de Valdés y las de sus padres ${ }^{43}$ y las desigualdades en el tratamiento de las figuras del monumento del Inquisidor, con ciertas torpezas, como algunas manos de las Virtudes del ático, desproporcionadas y toscas, serían consecuencia de las múltiples intervenciones que se registraron en estos sepulcros, desde sus comienzos hasta el final.

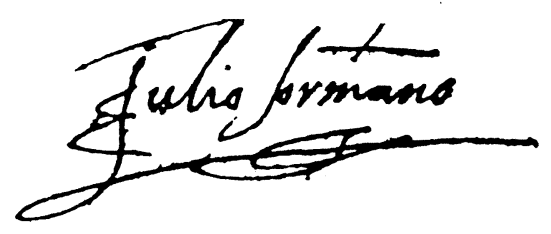

Firma de Julio Sormano

\section{La lauda del obispo don Bernabé y los rejeros Rodríguez y Plaza}

Desde principios del siglo XVI las diversas Constituciones Sinodales promulgadas en El Burgo de Osma reiteraron la prohibición de que se colocaran sepulcros exentos en el interior de los templos y recomendaron que se eliminaran los existentes ${ }^{44}$. Tales directrices cobraron aún mayor fuerza en las últimas décadas de la centuria, pues la ostentación mundana desplegada hasta entonces por el arte sepulcral ya no tenía cabida en ese espacio sagrado recuperado para la nueva espiritualidad emanada del Concilio de Trento ${ }^{45}$. La colocación de tales obras en lugares de especial significación dentro del recinto sagrado fue considerada además como un obstáculo espacial y visual para el desarrollo de las ceremonias litúrgicas. Esta nueva sensibilidad se materializó en ciertos cambios de ubicación, así como en la sustitución, e incluso la supresión, de algunas sepulturas que, por su configuración, su emplazamiento, o por su misma presencia fueron consideradas inadecuadas con respecto al nuevo talante contrarreformista.

En virtud de este criterio, en 1579 el cabildo catedralicio oxomense acordó eliminar el sepulcro del obispo don Bernabé (1331-1351) ${ }^{46}$, «porque ocupa el coro» ${ }^{47}$. En el mismo sentido se manifestó el obispo don Alonso Velázquez cuando efectuó su Visita Pastoral a la catedral en el mes de julio del año siguiente ${ }^{48}$. El monumento, presumiblemente obra de mediados del siglo XIV, estaba realizado en piedra, tenía la figura yacente del prelado por encima de la cama sepulcral y estaba rodeado por una reja ${ }^{49}$. Durante los años de su episcopado don Bernabé había costeado la continuación del antiguo claustro, el enlosado del interior de la catedral, el adorno de su exterior mediante pináculos y cresterías, y la colocación de una sillería de coro, en medio del cual se instaló su sepultura ${ }^{50}$.

${ }^{43}$ Proske, Beatrice Gilman, op. cit., p. 23 y Estella, Margarita, «Los Leoni...», p. 39.

44 Vid. Arranz Arranz, José, El Renacimiento sacro en la Diócesis de Osma-Soria, Burgo de Osma, 1979, p. 39. Noticias sobre los Sínodos Diocesanos oxomenses también se pueden encontrar en Hernández, José María: «Sínodos celebrados en la diócesis de Osma», XX Siglos, n. ${ }^{\circ} 33,1997 / 3$, pp. 60-68.

${ }^{45}$ Sobre el desmantelamiento de sepulcros exentos y la colocación de lápidas sepulcrales como la única memoria sepulcral admitida durante esos años en dicho templo, vid. también Redondo Cantera, María José, «Lauda sepulcral del obispo don Francisco Tello Sandoval», en La ciudad de seis pisos (Catálogo de la Exposición Las Edades del Hombre), El Burgo de Osma. Soria, 1997, p. 175.

${ }^{46}$ Sobre este obispo, vid. Loperráez Corvalán, Juan, Descripción histórica del Obispado de Osma con el catálogo de sus prelados, Madrid, 1788 (ed. fascímil, Madrid, 1978), t. I, pp. 286-294.

47 Arranz Arranz, José, loc. cit.

48 Archivo Catedralicio, El Burgo de Osma, Actos Capitulares, 1580-1584, fol. 60 y Loperraez Corvalán, Juan, op. cit., p. 448.

${ }^{49}$ Fue vendida en 1584-1585, Archivo Catedralicio, El Burgo de Osma, Cuentas de Fábrica, 1578-1668, fol. 69.

${ }^{50}$ Loperraez Corvalán, Juan, op. cit., p. 293. 
A comienzos de la década de 1580, gracias a uno de los legados dejados a la fábrica de la catedral oxomense por don Francisco Tello ( $† 1580$ ), que había ocupado la sede episcopal de Osma entre 1567 y 1578, se proyectaba la sustitución de la sillería de coro gótica del siglo XIV por otra acorde con el nuevo gusto clasicista ${ }^{51}$, que se labró entre 1585 y $1589^{52}$. Dentro de esta renovación del espacio coral se inscribía la eliminación de la cama sepulcral de don Bernabé. Pero el recuerdo de su actividad benefactora con respecto al templo impidió que desapareciera totalmente su celebración funeraria, tanto en lo que se refiere al ceremonial ${ }^{53}$ como al señalamiento de su sepultura. En 1580 el Cabildo repitió el acuerdo tomado el año anterior sobre la sustitución del sepulcro exento de piedra por una lauda metálica ${ }^{54}$. Ésta tenía que medir siete pies y medio de largo por tres de ancho, dimensiones que corresponderían con las de la sepultura abierta en el suelo del coro. Su coste se calculó en doscientos veinte ducados ${ }^{55}$.

A finales de ese año se pensó en encargar la lápida al rejero local Juan Rodríguez. Aunque ambas partes llegaron a un acuerdo sobre las condiciones, en febrero de 1583 la lápida todavía no estaba fundida ${ }^{56}$. Consta que entre 1582 y 1584 Rodríguez estuvo trabajando en El Escorial ${ }^{57}$, lo que le impediría cumplir con el compromiso.

En 1583 el cabildo propuso la fundición de la lauda al rejero y «laminero» madrileño Cristóbal de la Plaza ${ }^{58}$, quien años antes también había trabajado en El Escorial ${ }^{59}$ y que por entonces se hallaba preparando la lámina broncínea de don Francisco Tello Sandoval ${ }^{60}$. Pero a pesar de haberse comprometido a ello y de haber cobrado una suma a cuenta, pasados unos meses, Plaza tampoco llevó a cabo la de don Bernabé. Las grandes dificultades técnicas o económicas que se había encontrado para fundir la del obispo Tello le hicieron desistir de ello ${ }^{61}$.

El hecho de que los rejeros a los que el cabildo de Osma encargó la lauda de don Bernabé trabajaran en El Escorial es indicativo de la calidad de su trabajo en el arte de la rejería. En la España del Renacimento algunos rejeros, familiarizados con la fundición de metales, también se ocuparon eventualmente de trabajos en bronce, pese a la mayor dificultad y complejidad de su laboreo con respecto al hierro. A menudo repararon campanas, como hizo Plaza, pocos años más tarde con la mayor de la Catedral de El Burgo ${ }^{62}$. Pero algunos se sintieron capaces de llevar a cabo también representaciones figuradas. El mismo Plaza llegó a realizar la lauda funeraria del obispo don Francisco Tello, como se acaba de decir.

${ }^{51}$ Redondo Cantera, María José, «Lauda...». p. 175 y Archivo Catedralicio, El Burgo de Osma, Actos Capitulares, 1580-1584, fol. 418.

52 Archivo Catedralicio, El Burgo de Osma, Actos Capitulares, 1585-1591.

${ }^{53}$ A fines del siglo Xvil todavía se oficiaba un responso sobre su sepultura, al acabar las Horas, «todos los días feriales y fiestas de Santos simples», González Dávila, Gil, «Theatro Eclesiastico de la iglesia y ciudad de Osma...», en Theatro Eclesiastico de las iglesias metropolitanas y cathedrales de los reynos de las dos castillas..., t. IV, Madrid, 1700 , p. 50.

${ }^{54}$ Archivo Catedralicio, El Burgo de Osma, Actos Capitulares, 1580-1584, fol. 60.

${ }^{55}$ Id., fols. $315 \mathrm{v}^{\circ}$ y 317 .

56 Vid. las dos notas anteriores.

57 Andrés Martínez, Gregorio de, op. cit., pp. 97, 99, 125-126 y 133, y Bustamante García, Agustín, La octava maravilla..., pp. 508 y 557 .

${ }^{58}$ En 1580 se comprometió a hacer la reja de la capilla de Diego de Cáceres, en la iglesia del Hospital Real de Madrid, Notas tomadas por don Alejandro Martín Ortega de escrituras del A. H. de Protocolos de Madrid, t. V, 1991, p. 10. En 1585 se obligó a labrar la de la capilla de San Sebastián en la iglesia del convento de San Jerónimo de Madrid, donde estaba sepultado Clemente Gaitán de Vargas, Secretario de Felipe II, A. H. de P. de Madrid, leg. 996, fols. 594595.

${ }^{59}$ Andrés Martínez, Gregorio de, op. cit., pp. 68 y 71 y Bustamante García, Agustín, La octava maravilla..., p. 543.

${ }^{60}$ Redondo Cantera, María José, «Lauda sepulcral...», p. 175.

${ }^{61}$ Archivo Catedralicio, El Burgo de Osma, Actos Capitulares, 1580-1584, fol. 373 y Cuentas de Fábrica, 1578-1668, Cuentas de $1582-1583$, fols. 50 v. $^{\circ}$ y 53 v..$^{\circ}$

${ }^{62}$ Redondo Cantera, María José, «Lauda sepulcral...», p. 175. 
Se conocen otros ejemplos en el arte español en los que el autor de una memoria sepulcral en bronce fue un rejero ${ }^{63}$. El mejor exponente de ello, pero también la excepción, por la gran calidad que alcanzó su trabajo en las figuras orantes de las damas Cabrera, en el presbiterio de la iglesia conventual de San Francisco, en Medina de Rioseco (Valladolid), fue Cristóbal de Andino ${ }^{64}$. La línea que éste inició en la escultura en bronce ${ }^{65}$ no tuvo continuidad. En los otros dos casos documentados en los que sabemos que fue un rejero el autor de la memoria funeraria con representación del difunto ${ }^{66}$, ésta adoptó la sencilla bidimensionalidad de la lauda, y la factura de su relieve estuvo muy lejos de alcanzar la finura que tenía este tipo de obras cuando fueron realizadas por escultores o talleres italianos.

\section{Julio Sormano, autor de la desaparecida lauda del Obispo don Bernabé}

Pese a la renuncia de los rejeros Rodríguez y Plaza para fundir la lauda de don Bernabé, el cabildo oxomense siguió interesado en ello. En septiembre de 1583 acordó indagar sobre la posibilidad de que hubiera algún artista en Valladolid que se hiciera cargo de ella ${ }^{67}$.

Pero no debió de encontrarse, ya que finalmente se contrató con Julio Sormano, aprovechando la presencia de éste en El Burgo de Osma durante los meses de mayo y junio de 1584. Los datos procedentes del archivo catedralicio que documentan la lauda como obra de Sormano identifican a éste además como «extranjero» y «escultor». En la formalización del concierto salieron como fiadores del escultor Juan de Naveda, maestro de cantería y vecino entonces de Aranda de Duero, Antonio del Castillo, pintor vecino de El Burgo, y Juan de Espinosa, vecino de Roa (Burgos). El cabildo pagó a Sormano los doscientos cincuenta ducados acordados -un precio algo superior al previsto en un principio-, pero le satisfizo tanto la obra que le añadió una gratificación ${ }^{68}$. La lápida contenía la representación yacente de don Bernabé, vestido de pontifical, en bajorrelieve. Alrededor corría una inscripción que copió González Dávila: «AQUI YACE EL REBERENDO SENOR DON BERNABE, OBISPO QUE FUE DE OSMA DE BUENA MEMORIA. FALLECIO ANO DE MIL Y TRESCIENTOS Y CINCUENTA Y UNO» ${ }^{6}$.

Como consecuencia del traslado del coro hacia los pies del templo, la lauda quedó en la Via Sacra. Allí sufrió un gran desgaste, por lo que en 1885 se decidió quitarla y sustituirla por una de piedra $^{70}$. En 1906 la lauda metálica fue vendida y desapareció ${ }^{71}$.

${ }^{63}$ Redondo Cantera, María José, El sepulcro en España en el siglo XVI. Tipología e iconografía, Madrid, 1987, pp. 72-73.

${ }^{64}$ Villalón, Cristóbal de, Ingeniosa comparación entre lo antiguo y lo presente, en Sánchez Cantón, Francisco Javier, Fuentes literarias para la Historia del Arte Español, t. I, Madrid, 1923, p. 30.

${ }^{65}$ Puesto de relieve por Bustamante García, Agustín, «Datos de escultores de los siglos XVI y XVII», B.S.A.A., t. XLIV, 1978, p. 308

${ }^{66}$ Además de la lauda de don Francisco Tello, cf. supra, la de don Gabriel Zaporta, en la Seo de Zaragoza, documentada por San Vicente, Ángel, «La capilla de San Miguel, del patronato Zaporta, en la Seo de Zaragoza», A.E.A., t. XXXVI, 1963, pp. 117-118.

${ }^{67}$ Archivo Catedralicio, El Burgo de Osma, Actos Capitulares, 1580-1584, fol. 378. Pese a ello Juan Rodríguez aún cobró cierta cantidad por este concepto en 1584 o 1585, Cuentas de Fábrica, 1578-1668, fol. 34 v.‥

${ }^{68}$ La suma de 7.480 maravedís se añadió al precio concertado, lo que sumó un total de «cien mil y novecientos maravedis que se dieron a julio sormano sculptor por la lamina que esta puesta en el choro sobre la sepultura del obispo don bernabe», Archivo Catedralicio, El Burgo de Osma, Cuentas de Fábrica, 1578-1668, Cuentas de 1584-1585, fol. 75. Algún donativo, como el de don Alonso Velázquez, por entonces arzobispo de Santiago y anterior obispo de El Burgo de Osma, ayudó a sufragar los gastos, tal como aparece en las cuentas de los bienios 1584-1585 y 1586-1587.

${ }^{69}$ Op. cit., p. 50 y Loperráez Corvalán, Juan, op. cit., p. 294.

${ }^{70} \mathrm{Ni}$ siquiera puede verse ésta en la actualidad, debido al nuevo enlosado de mármol con el que se ha cubierto el suelo de los dos tramos situados entre el coro y el presbiterio.

${ }^{71}$ Núñez Marqués, Vicente, Guía de la S. I. Catedral del Burgo de Osma y breve historia del obispado de Osma, Burgo de Osma, 1949, pp. 37 y 104-105. 
Aunque, como se ha dicho más arriba, con excepción de su intervención en las piezas de bronce para la custodia, no se conoce ningún testimonio documental que vincule a Julio Sormano con la decoración escultórica de El Escorial, parece más que probable que la estancia o el paso del italiano por El Burgo de Osma estuviera en relación con las canteras de la zona que por esos años estaban proporcionando abundantes materiales para el monasterio. Desde 1578, tras la inspección por Comane de las canteras pertenecientes al monasterio de Espeja, situadas en el término de Espejón (Soria), salieron numerosas piezas para la custodia, el retablo, los sepulcros reales y otras partes en el monasterio de El Escorial ${ }^{72}$. El protagonismo del jaspe de Espeja en la estructura arquitectónica del retablo estuvo presente desde el mismo momento de la traza y el contrato de éste en $1579^{73}$. Dos años antes, este material se encontraba entre aquellos con los que debía confeccionarse el arco sepulcral de don Diego Espinosa de los Monteros, en la iglesia parroquial de Martín Muñoz de las Posadas (Segovia), contratado por Pompeyo Leoni y subcontratado por Marogia, Comane y Guideti en lo correspondiente al marco arquitectónico ${ }^{74}$, lo que indica que la cantera ya se encontraba en funcionamiento. En 1579 Felipe II ordenó que su explotación se reservara en exclusiva para El Escorial ${ }^{75}$. En los años siguientes varios oficiales italianos, supervisados por Comane, trabajaron en Espeja ${ }^{76}$, donde no sólo se ocupaban de la extracción de la piedra, sino que también iniciaban la talla de las piezas ${ }^{77}$. Además de suministrar el material de distintos elementos de la custodia y del retablo ${ }^{78}$, en cuyas partes de jaspe se trabajaba muy activamente en $1584^{79}$, en ese mismo año los yacimientos sorianos proporcionaron elementos para otros sectores de la iglesia y del monasterio igualmente significativos, como los nichos sepulcrales de la capilla mayor y el oratorio del Evangelio ${ }^{80}$. Al mismo tiempo que la de Espejón, también funcionó en tierras sorianas la cantera de Huerta, próxima a El Burgo de Osma, de donde se extraía un jaspe rojo de gran calidad ${ }^{81}$.

A la vista de estos datos, parece evidente que la presencia de Julio Sormano en El Burgo de Osma en 1584 se justifica por su probable actividad en Espejón o en Huerta, ocupado quizá en la preparación de las piezas que habían de enviarse a El Escorial, aunque falta confirmación documental sobre ello. La hipótesis de su estancia en las canteras con objeto de cumplir un encargo

\footnotetext{
72 «Memorial de Jacome de Trezzo...», p. 66; Vicuna, Carlos, Los minerales de El Escorial, El Escorial, 1929, p. 101; y Cano de Gardoqui y García, José Luis, La construcción..., pp. 363 y 223-228.

${ }^{73}$ Vid. los documentos publicados por Bustamante García, Agustín, «Las estatuas...», Anuario..., t. V, pp. 50-51.

${ }^{74}$ Plon, Eugène, op. cit., pp. 400-401 y Pérez Pastor, Cristóbal, op. cit., pp. 26 y 199-211.

75 A. G. S., C. y S. R., leg. 279, fol. 601. Agradezco este dato al Dr. Cano de Gardoqui. Una vez terminado el retablo de El Escorial, a partir de 1588 el jaspe de Espejón fue empleado de nuevo para encargos privados, sobre todo por Juan Antonio Marogia, como, por ejemplo, en los arcos sepulcrales de Lope de Avellaneda, en el monasterio de Espeja, o en los de los Marqueses de Aguilar, en la Colegiata de San Miguel, en Aguilar de Campoo (Palencia). Sobre ellos vid. García Chico, Esteban, «El sepulcro de don Lope de Avellaneda», Celtiberia, n. ${ }^{\circ} 25,1963$, pp. 116-119 y Estella, Margarita, «Artistas de los sepulcros de los Marqueses de Aguilar y procedencia de los Condes de Fuensalida, documentados», Homenaje al Profesor Martín González, Valladolid, 1995, pp. 329-330.

${ }^{76}$ Cano de Gardoqui y García, José Luis, La construcción..., p. 397. En 1579 la gran actividad que se desarrolló allí para abastecer la demanda escurialense obligó a nombrar un sobrestante para controlar el trabajo y los pagos, lo que ya estaba previsto en el contrato del retablo, Portabales Pichel, Amancio, Los verdaderos..., pp. CXL-CXLI; Bustamante García, Agustín, La octava maravilla..., pp. 415 y 454, y «Las estatuas...», p. 51.

77 Santos, Fray Francisco de los, Descripción del Real Monasterio de San Lorenzo del Escorial..., Madrid, 1681, p. 107; Ximenez, Fray Andrés, Descripción del Real Monasterio de San Lorenzo del Escorial..., Madrid, 1764 (ed. facsímil, Madrid, 1984); y Quevedo, José, Historia del Real Monasterio de San Lorenzo llamado comunmente del Escorial..., Madrid, 1849 , p. 52.

${ }_{78}$ Datos sobre la llegada de jaspe procedente de Espeja, en Bustamante García, Agustín, «Las estatuas...», Anuario..., t. VI, p. 160.

${ }^{79}$ Cano de Gardoqui García, José Luis, «Relación de las obras de cantería, carpintería y albañilería realizadas en la Fábrica del Monasterio de El Escorial (1562-1587)», La Ciudad de Dios, vol. CCVI, n. ${ }^{\circ} 2$, 1993, p. 430.

${ }^{80}$ Cano de Gardoqui García, José Luis, «Relación...», p. 431.

${ }^{81}$ Cano de Gardoqui García, José Luis, La construcción..., pp. 223-224.
} 
privado encuentra la objeción del monopolio real ejercido por entonces sobre ellas. De todos modos, la forma «Julio Petreyo» con la que le denomina la documentación catedralicia en una ocasión ${ }^{82}$, podría estar en relación con su actividad de «pedrero» o «lapidario», especialista en la labra de materiales marmóreos, como ya se podía suponer por su intervención en los sepulcros de los Valdés.

En el encargo de la lauda de don Bernabé a Julio Sormano pudo intervenir también otro factor que ligaba a El Burgo de Osma con El Escorial y el ambiente cortesano. Entre 1583 y 1593 ocupó la sede episcopal oxomense don Sebastián Pérez, que había sido con anterioridad Lector de Teología en el Colegio escurialense y maestro del Archiduque don Alberto de Austria ${ }^{83}$. Si el prelado estaba al tanto de que Sormano había colaborado con Leoni e intervenido en la Custodia de El Escorial podría haber informado al cabildo sobre la idoneidad del italiano para llevar a cabo una obra broncínea.

A través de los datos revisados y presentados aquí, se confirma la nada desdeñable doble faceta de Sormano como escultor capacitado para esculpir el bronce y los materiales marmóreos, en la misma línea que los Leoni y algunos de sus colaboradores, como César Villa. De todos modos, Julio Sormano continúa siendo uno de los miembros del círculo de Pompeyo Leoni que resulta más enigmático, debido a la ausencia de su mención en los documentos relativos a El Escorial. Quizá el hallazgo de más noticias sobre este artista romano, procedentes de fondos archivísticos españoles o italianos distintos a los consultados hasta ahora, permitan en el futuro perfilar su personalidad artística y su actividad en España con mayor precisión.

82 Archivo Catedralicio, El Burgo de Osma, Actos Capitulares, 1580-1584, fols. 418-422. No descartamos la posibilidad de una confusión en la grafía o en la lectura de la palabra «petreyo».

${ }_{83}$ Villacastín, Fray Antonio, Memorias, en Zarco Cuevas, Fray Julián (ed.), Documentos para la Historia del Monasterio de San Lorenzo el Real de El Escorial, t. I, Madrid, 1916, pp. 58-59, González Dávila, Gil, op. cit. y Loperráez Corvalán, Juan, op. cit., pp. 450-461. A su muerte, en 1593, fue enterrado en la capilla mayor de la catedral de El Burgo de Osma, bajo una lápida de jaspe. 